\title{
Study of Some Characteristics Related to the Sexual Reproduction in Autotetraploid Vicia narbonensis
}

\author{
Hassen Hamadi (Corresponding author) \\ Institut National de la Recherche Agronomique de Tunisie \\ Rue Hédi Karray, 2080- Ariana, Tunisia \\ Tel: 216-71-230-024Ｅ-mail: hassen.hamadi@iresa.agrinet.tn; hassen.hamadi@yahoo.fr \\ El Bok Safia \\ Faculté des Sciences de Tunis \\ Laboratoire de génétique des populations et ressources biologiques. 2092 \\ El Manar II, Tunis \\ E-mail: safia1elbok@yahoo.fr
}

\begin{abstract}
Some parameters such as frequency of pod formation, average number of seeds per pod and percentage of empty pods were used to evaluate the variation of fertility in autotetraploid Vicia narbonensis. The results showed that the autotetraploid and diploid parents had the same number of ova per gynaecium. However, the tetraploid seedling produced fewer seeds per pod and per seedling than their corresponding diploids; the poor fertilization of many ovum was probably behind the decline of fertility in the autotetraploids. Several factors may be involved: the low efficiency of diploid pollen (related to a relatively slow growth of the pollen tubes), an unbalanced meiosis for a great number of mother cells of pollen grains and a significant morphological modification of the reproductive system due to the passage from the diploid to the tetraploid state.
\end{abstract}

Keywords: Autotetraploid, Vicia narbonensis, Chromosomical configuration, Meiosis, Straggler chromosome, Vetch, Anaphase, Self pollination, Free pollination, Semi-arid area, Pollen viability, Pollen germination, Fertility, Flower ration, Tunisia

\section{Introduction}

According to the available archaeological knowledge, the vetches would have been cultivated since the eight ${ }^{\mathrm{h}}$ century before Jesus-Christ (Zohary and Hopf, 1988). For Vicia narbonensis, its use goes up to the second century before Jesus-Christ (Schulte-Motel, 1972). In Tunisia, the main species as Vicia sativa L, Vicia villosa Roth. and Vicia narbonensis L, were at the origin of the development of significant forage surfaces across the country (Hassen, 1994). But in the past decade, the cultivated areas reserved for these species continued to decline in favour of other species. The absence of improved varieties adapted to an intensive use was the principal cause of the decreasing areas.

The early selection work done on vetches, mainly on Vicia sativa ssp sativa L. through the agronomic evaluation of local populations has enabled to the release of the variety named 'common vetch'. The objective was to improve the quality of dry matter and the resistance to the climatic stresses in the local material.

After three decades of use, the 'common vetch' variety did not feet either the cropping requirements or the new forms of farmer requirements. Furthermore, it has showed a high sensibility to shading, a very slow winter development and a delayed period of maturity compared to the late oat varieties with which it was associated.

The difficulties in overcoming these agronomic constraints could be attributed either to the weak of methods used to exploit the potential of genetic variation in the local material or to the fact that the variety has reached the optimum of its performance.

The economic importance of vetches has imposed a continuous investigation for the regulation of its outputs, the improvement of its fodder qualities and its adaptation to various types of conditions. New sources of variability can be obtained by the study of the natural populations distributed over the world (Maxted, 1995), the hybridization (Raina et al., 1989) or by the genomic changes for the creation of polyploid forms in particular the 
autoteraploids. This path has been considered and tested by various scientists; it has allowed in certain cases the achievement of a considerable genetic progress.

Indeed, the passage of the diploid state to the autoteraploïd one affected a great number of characters and had led to the creation of new genotypes in order to improve the existing variability. The presence of 4 allelic locations for the same locus provided a big number of combinations and reduced the modifications of the structure of the populations (Mansat and Picard, 1966).

However, one of the major constraints to the extension of the autoteraploids is the weakness of their seed production. The analysis of the main factors affecting the fertility of the autoteraploïds has been the subject of several works such as: Picardy and Berthaut (1965), Povilaitis and Boyes (1956) on Trifolium pratense L; Béji (1980) on Hedysarum coronarium L; Martin and Gonzalez (1981) and Alexy (1996) on Vicia faba L. and Bourgeois (1980) on Vicia narbonensis L. The conclusions, even they were different from one to another, they highlight the complexity of this phenomenon.

To evaluate the reproductive potentialities of the autoteraploïds plants in Vicia narbonensis (local population), we estimated the fertility of plants subjected to 2 mating systems: controlled self pollination and free pollination. The fertility of the plants was measured by the frequency of pod formation, the average number of seeds per pod, the average number of seeds per flower and the percentage of empty pods. These indices have been used in Medicago sativa L. (Dattee, 1975), Hedysarum coronarium L. (Baatout, 1982; Chriki, 1986) and Lathyrus sp. (Chaibi et al., 1985; Ben Brahim, 1990) in order to estimate their ability to the sexual reproduction.

\section{Materials and methods}

\subsection{Plant Materials}

The diploid population $(2 n=2 x=14)$ was collected in the Utica area (North-east of Tunisia) in semi-arid area with mild winter. Individuals representing this population were characterized by an ascending habit and smooth leaves with green-pale colour and inserted according to a distich alternate phyllotaxy. The flowers $(1.8$ to $2.4 \mathrm{~cm}$ in length) were solitary, rarely paired or in clusters with a purplish corolla.

The autotetraploid population $(2 n=4 x=28)$ resulted from the treatment with colchicine of the diploid population. It differs from the diploid population by a general gigantism of the vegetative and floral growth, a denticulate foliar limb and presented a curving in the top in which we founded a micron characterizing the tetraploid forms. The flower is large (an average of $2.64 \mathrm{~cm}$ in length), solitary and intensively coloured.

\subsection{Methods}

\subsubsection{The experimental design}

Sowing was carried out in October 30 of 2005 at a rate of 2 seeds per pot. The substrate of the culture consisted of a mixture of sand and compost (2:1) sterilized with the drying oven at a temperature of $105^{\circ} \mathrm{C}$ during 48 hours. The experimental design was a randomized block with 3 replications. Each replication was represented by 5 pots (10 plants each).

\subsubsection{Reproductive biology}

Two modes of reproduction have been studied in diploid and tetraploid plants at the $\mathrm{C} 2$ stage: self pollination with tripping and free pollination. For each mode, 15 adult plants from tetraploid plants (C2) and 15 from diploid ones (check) were selected for a critical analysis of their floral biology. On each plant, 20 flowers with corolla barely visible were manipulated.

\section{Self pollination with tripping}

Flowers were tripped using a fine grip to remove the upper part of the hull which entirely enveloped the stamens. This action allowed the contact between the pollen and the stigma of the flower. The grip is sterilized with alcohol $95^{\circ} \mathrm{C}$ between 2 uses. The tripped flowers were then wrapped in perforated cellophane bags to avoid the rotting of the bodies.

\section{Free pollination}

In this experiment, the flowers were selected and identified from the blooming stage and left to free pollination. Like the majority of fodder and pastoral legume plants, the flowers of diploids and tetraploid Vicia narbonensis are visited by pollinators (Morthorpe and Jones, 1990). These pollinators are represented by the domesticated bee (Apis mellifeca L.) and a specific plant bumblebee (Bombus terrestris L.) that visit large legume flowers (Hassen and Seklani, 1 992). 
For these two experiments, the following parameters were recorded on one individual plant: total number of pods (NP), total number of seeds (NS), average number of seeds per pod (S/P), number of pods per flower (P/F), percentage of empty pods (PEP), weight of 10 seeds (W10), weight of seeds per plant (SW/P) and length of the pod (LP).

\subsection{Study of the pollen}

\subsubsection{Viability of the pollen}

Pollen is collected from the anthers of flowers in early development. The indehiscent anther was crushed on a slide of glass containing a drop of the dye of Alexander (Alexander, 1969). When observed under microscope, viable pollen had red colour while empty pollen had green colour.

\subsubsection{Pollen germination test}

To estimate the percentage of germinated pollen, the protocol of the hanging drop was followed: 2 - 3 anthers were squashed on a slide in a drop of aqueous solution with $20 \%$ of sucrose. After removing the debris from the anthers and homogenizing the preparation by using a clean grip, the slide is turned over on a container of distilled water. Germination occurred under atmospheric conditions of the laboratory. Germination is noted at the end of 2 hours using a photonic microscope (10 X 40).

\subsection{Observation of the meiosis}

The study of chromosomal pairing in metaphase I and anaphase abnormalities in mother cells of the pollen seeds (CMP) was carried out according to the method described by Jahier et al., (1996). Since the flowers of the same inflorescence have different stage of development, all inflorescences with no flowers were harvested. They were collected in the axils of the last apical leaf.

\subsection{Statistical analysis}

The data were subjected to analysis of variance to determine the importance of various factors on the variability of the studied characters according to a fixed model with two factors of classification (level of ploidy and mode of reproduction). The computer program used was SAS (Statistical Analysis System, 1990) with ANOVA procedure.

A mean comparison test was used for some data such as the number of ova by gynaecium and number of seeds by pod for tetraploid and diploid plants. The Calculations were made by the computer program Msustat (version 3.20) with the procedure "Tsingle" (tests for single samples).

To evaluate the relationship between the chromosomal configurations during the meiosis and certain parameters of fertility (number of pods per plant, percentage of empty pods, total number of seeds per plant, average number of seeds per pod and the seed weight per plant), the simple correlation coefficient " $r$ " was used. The calculation of "r" was carried out by the program SAS (Statistical Analysis System, 1990) with the procedure "Corr".

\section{Results and Discussion}

\subsection{Variability of the fertility parameters}

The analysis of the variance applied to the all data revealed significant effects of the ploidy and the mode of the breeding system on the variation of the studied parameters. However, certain traits such as the weight of 10 seeds and the length of the pod were not affected by the reproductive system. These two parameters were related to the ploidy level (Table 1).

The average weight of 10 seeds was estimated at 4.2 and 3.1 grams for respectively, the diploids and the tetraploids. Whatever the reproductive system, the tetraploid plants have significantly long pods $(5.7 \mathrm{~cm})$ than their corresponding diploids $(4.8 \mathrm{~cm}$ ). These two parameters (length of the pod and the weight of 10 seeds) are changing and accurately describe the different levels of ploidy in this species. The difference between diploids and tetraploids for these characters is maintained from one generation to another $(\mathrm{C} 0, \mathrm{C} 1$ and $\mathrm{C} 2)$ regardless the system of pollination. This result was on line with several other results on the same subject. In barley, Assad and Cachon (1965), after a cytological analysis of the descent of a certain number of plants treated with colchicine; note that the best correlative character of the degree of ploidy is represented by the size and the shape of the seed. Berkov (2001), within the framework of a study on dimensions and the high content in alkaloids of seeds of Datura innoxia Mill., Datura stramonium L. and Hyoscyamus Niger L. reveals that the autoteraploïds created in these species present large seeds than those of their corresponding diploids.

In addition, the tetraploids produce very few seeds by plant. This reduced number of seeds is related to a lower pod to flower ration $(\mathrm{P} / \mathrm{F})$, a very reduced $\mathrm{S} / \mathrm{P}$ ratio and a high percentage of empty pods (Table 1). In fact, 
empty pods represent more than $60 \%$ of the whole number of analyzed pods in tetraploid plants against only $7 \%$ in diploids parents (Figure 1). Moreover, the rate of flowers giving pods $(\mathrm{G} / \mathrm{F}$ ) is higher in diploid forms whatever the reproductive system (0.93 to 1.00$)$. In autotetraploid forms, these rates are significantly lower; they are around 0.7 and 0.93 respectively, in free and self pollination. Self pollination that tries to overcome the mechanical difficulty opposing the modifications of floral morphology (caused by the passage from the diploid state to the tetraploid one) allowed the majority of the flowers to have a correct pollination since the pollen grain are putted directly in contact with the stigma of the same flower. These morphological modifications associated with the change of the level of ploidy were revealed by Béji (1980) on Hedysarum coronarium L.

Diploid pods had approximately 2 times more seeds than tetraploid ones and the difference is higher in free pollination (Table 1). Moreover, $87.5 \%$ of the pods observed in tetraploid plants contain a seed per pod on average. In diploid plants, we counted up to 7 seeds per pod; the most frequent number is 4 seeds per pod (Figure $1)$.

For the parameters such as pods to flowers ratio $(\mathrm{P} / \mathrm{F})$ and percentage of empty pods (PEP), a significant interaction between the level of ploidy and the reproductive system is highlighted in tetraploid plants. For the other characters, this effect of synergy does not exist. A difference in behaviour between diploid and tetraploid seems to exist according to the reproduction system. Table 2 presents the evaluation, for each ploidy level of all the parameters studied in free and self pollination with releasing.

For diploid Vicia narbonensis L., the reproductive system does not affect the variation of the parameters of fertility. The diploids are shown to be particularly fertile in self and free pollination. For autoteraploids, the reproductive system seems to play a significant role on the studied parameters. Self pollination seems to improve the number of seeds per plant, the frequency of formation of pods, the number of seeds per pod and the number of seeds per flower. However, it reduces the percentage of empty pods per plant. This observation was revealed by various authors on different plants: Bingefors and Eskilsson (1962) on tetraploid Trifolium pratense and Hassen and Seklani (1992) on Medicago sativa L. This result suggests that in natural pollination, one of the problems which can be at the origin of the low of fertility in tetraploid plants would be a problem of fecundation.

The role of fecundation on the fertility of autotetraploïds was shown by the examination of the ratios: number of ova by gynaecium and number of seeds by pod. The decrease of the number of seeds per pod in autotetraploïds suggests that their ovaries contain fewer ova than in diploids. For that, we counted the number of ova on the gynaecium of 15 tetraploid and 15 diploid plants. The test of mean comparison for this criterion, has shown that the difference is not significant (Table 3)

No relationship exists between the number of seeds per pod and the number of ova per ovary in autoteraploïd Vicia narbonensis under self or free pollination. The abortion of the majority of the ova is due probably to a bad pollination. This hypothesis suggests some questions about the pollen activity in autoteraploïd plants (in particular the malformation of seeds). Being given the small percentage of in vitro germination of the pollen in tetraploids, it is allowed to suggest that pollen germinates badly on the style and fertilizes a limited number of ova. The bad fecundation could be also due to the lack of pollen deposited on the stigma of tetraploid flowers (Bourgeois, 1980). Being few fertile and fewer on the stigma, diploid pollen cannot ensure a suitable fecundation of the embryonic bag. This results in an abortion of the majority of ova and the obtaining of few seeds in the pod.

The study of the reproductive potentialities of Vicia narbonensis has detected 3 main problems behind the low for efficiency of pollen autotetraploïds: a morphological and physiological origin, a genetic origin and an origin related to the structure of diploid pollen.

\subsection{Causes related to the structure of pollen}

\subsubsection{Grain pollen shape}

The pollen of Vicia narbonensis autotetraploïd is formed by a mixture of grains with different shapes: oval, round and tetrahedral, in varying proportions. The oval shape, characteristic of the diploids, was represented in minor proportion (18\%) while tetrahedral shape (aberrant grains) is predominant $(76 \%)$ and is extremely variable from one individual to another ranging from 21.14 to $84.16 \%$ (Figure 2). According to Béji (1980), this particular shape of the pollen is due to a total non disjunction of the colporus at the meiosis state.

Judged by staining with carmine acetic first, followed by germination in a hanging drop of sucrose solution at $20 \%$, the fertility of the aberrant grain is significantly lower than that of the pollen in diploid plants (Table 4). However, the coloration of anthers with hematoxylin showed normal nuclear contents and discarded the hypothesis of empty or aborted grains in order to explain this failure of germination. A partial sterility of the 
aberrant grains seems to be rather than of genetic origin. The plants with big proportions of aberrant grains produced, by self pollination, descendants having pollen with mainly tetrahedral or round shape. Among this descendant, the individuals containing more than $20 \%$ of aberrant grains provide the lowest ratio of autogamy report whatever the reproductive system.

\subsubsection{Shape of the pollen tube}

In tetraploids, pollen tube is relatively short compared to that of the diploids ( $87 \mu \mathrm{m}$ for tetraploid vs. $118 \mu \mathrm{m}$ for diploids) (Figure 3). At the time of fecundation, the pollen tube, in addition to its slow growth, will find more difficulties to cross its own style in order to reach the embryonic bag and to achieve a suitable pollination of the oosphere. This hypothesis was confirmed by the examination of the pods collected on tetraploid plants in which the first seed (at least) always failed (Figure 4).

\subsection{Causes of genetic origin}

To explain the reduced fertility of diploid pollen, it was interesting to examine the meiotic configurations at the metaphasis I and the anaphasis I that have been considered by several authors as the main causes of sterility in many polyploidy species. In Trifolium pratense autotetraploïd, Povilaitis and Boyes (1956) assume that the presence of a high percentage of failed pollen abortion under the influence of a genetic factor whose action would reduce the formation of viable gametes. Also, Alexy (1996) reveals that the decline of fertility in tetraploid Vicia faba is due to an unbalanced meiosis leading to the formation of gametes partially or completely non-functional.

The comparison of the different meiotic configurations observed in tetraploid plants revealed a high significant difference between plants with regard to the frequency of associations into bivalents and quadrivalents. For the trivalent and monovalent, this difference was not significant (Table 5). The variability between plants can be explained by the fact that the initial population treated by the colchicine could probably contain plants with different genotypes. Moreover, the presence of a relatively small low number of multivalent in small cells analysed (Table 5) supposed that the separation of the homologous chromosomes at Vicia narbonensis autotetraploïd could take place in stages prior to metaphase I.; more investigations on the level of the diplotene and diakinesis stage may provide additional answers.

The incidence of the meiotic configurations on the fertility of tetraploid was evaluated by the correlation coefficient (r) calculated between the frequencies of chromosomal associations (in metaphase I) and certain parameters of fertility which were not affected by the univalent or trivalent. This was probably due to the small proportion of univalent $(0.69)$ and trivalent $(0.32)$ in the cells. The quadrivalent associations (an average of 2.55) seem to play a dominating role on these parameters. The tetravalent are associated with a poor grain yields and high a percentage of empty pods. They act, firstly by their importance in the CMP; it was demonstrated that since the mean number of tetravalent exceeded the 3 per CMP in a plant, all the parameters of fertility are affected (low rate of pod formation, high percentage of empty pods...).

Tetravalent can also act through the abnormal anaphases which is often the cause. Among these anomalies, stragglers were observed in certain cells (Figure 5A). The majority of these stragglers didn't join the batches anaphase at the time of the division of the genetic inheritance between the cells girls, since permanent anaphase bridges were observed at the telophasis stage (Figure 5B). Moreover, some of these stragglers form micronuclei and are involved in the formation of abortive gametes (pollens or ova).

The frequency of the stragglers varies from 15 to $18 \%$ respectively, in anaphasis I and anaphasis II while that of the anaphasic bridge is lower. It is between $1.8 \%$ and $5.6 \%$ respectively, in anaphase I and anaphase II. The micronuclei were observed in $7 \%$ of the analysed tetrads. On a sample of 11 tetraploid plants whose the pollen mother cells (CMP) showed, a significant number of multivalent (higher than 3) or an irregular disjunction of certain chromosomes (laggards, bridges...), or the 2 at the same time, the rates of pollinic viability and fertility were very low. This observation confirms the very significant role of the meiotic configurations and the abnormalities of the anaphase I on the gametogenesis and by consequent on the fertility of tetraploid Vicia narbonensis $\mathrm{L}$.

\subsection{Causes related to the physiology and the morphology of the tetraploid genotypes}

In addition to the genetic factors, certain morphological and physiological parameters may contribute to reduce the fertility in this species:

* throughout their very spread growing cycle, the autotetraploïds produce a significant proportion of flowers at the end of their cycle on new spring growing sheet when climatic conditions are not favourable to pollination. Moreover, when examined under the microscope, flowers show empty anthers and often didn't give pods. 
* the passage from the diploid state to the tetraploid one was associated with gigantism of all the vegetative and floral growth. The changes occurred at the reproductive system represented an important constraints for pollinators that have find mechanical difficulties to open and pollinate the flower. According to Bingefors and Eskilsson (1962) on Trifolium repens L.; Béji (1980) on Hedysarum coronarium L.; Hassen and Seklani (1992) on Medicago sativa L., and Dirk (1995) on Vicia narbonensis L., and in absence of obstructions, these pollinators are effectively involved in improving fruit set in legumes whatever their reproductive system. Performed manually on local tetraploid Vicia narbonensis tetraploid population, initiation of flowers has led to a significant improvement in the pods / flowers ratios which becomes very close to that of diploids (0.93).

\section{Conclusion}

The previous results showed that the seed production is relatively low among tetraploid Vicia narbonensis. The difficulties lie in the level of fertilization since the number of ova and flowers didn't differ between diploids and tetraploids. Many factors are behind this poor fertilization but the genetic cause seems to be more prevalent. Bad chromosomal pairing and no synchronized segregation of some chromosomes are responsible for the formation of high proportion of sterile pollen.

In order to better use the obtained teraploidy, it is advisable to know how and in what sense, the different genotypes will progress in terms of fertility. In this sense, the evaluation of the different parameters related to the fertility must be investigated in subsequent and further generations $(\mathrm{C} 3, \mathrm{C} 4, \mathrm{C} 5 \ldots)$ until the genetic balance. The rapidity to achieve this balance as well as the level recorded for all these parameters are the criteria that will help to determine the future of the tetraploid population.

\section{References}

Alexander, M. P. (1969). Differential staining of aborted and non aborted pollen. Stain technique, 44 3: 117-122.

Alexy, Y. K. (1996). Colchicine induced tetraploid of Vicia faba L. Fabis. Newslettre, 38: 21-24.

Assad, S. et Cachon, H. (1965). Recherches préliminaires sur orge pour une tentative d'amélioration des traitements par la colchicine. Ann. Amélior. Plantes, 15 (I): 5-21.

Baatout, H. (1982). Analyse du polymorphisme dans le complexe Hedysarum spinossimum. Bull. Soc. Bot. France. Lettres Botanica, p:155-165.

Béji, M. (1980). Etude des autotétraploïdes d'Hedysarum coronarium L. induits expérimentalement. Doc. Sp. Fac. Sci. de Tunis, 64p.

Ben Brahim, N. (1990). Biologie florale et variabilité morphologique et enzymatique chez trois espèces de Lathyrus: L. cicera L., L. articulatus L., et L. ochrus D.C. Doc. Spécial. Gén. Fac. Sci. de Tunis, 99 p.

Berkov, S. (2001). Size and Alkaloid Content of Seeds in Induced Autotetraploids of Datura innoxia, Datura stramonium and Hyoscyamus niger. Pharm. Biol, 39 (5): 329-331

Bingefors, S. and Eskilsson, C. (1962). Pollination problems in tetraploid red clover in central Sweden. $Z$. Pflanzucht 48: 205-214.

Bourgeois, F. (1980). Tetraploid plants from Vicia faba L. and Vicia narbonensis L., using colchicine treatement. Fabis Newslettre, 2: 25-26.

Chaibi, A., Delbos, M. and Combes, D. (1985). Priliminary studies on the genetic variability of three perennial species of Lathyrus (L. tuberosis L., L. sylvestris L., et L. latifolius L.): chromosomal and reproductive aspects. (ed).

Chriki, A. (1986). L'héridité des anthocyanes florales chez Hedysarum coronarium L. Hedysarum carnosum Desf. et Hedysarum capitatum Desf. Asch et Gr. Doct. d'état. Univ. de Pau et des Pays de l'Adour, 229 p.

Dattée, Y. (1975). Facteurs génétiques liés à l'auto et à l'interfertilité chez Medicago sativa L. Th. Doc. Univ. De Paris VI 208 p.

Dirk, E. (1995). The toxicity of Vicia species and their utilisation as grain legumes. Edit. Co-operative Centre for Legumes in Mediterranean Agriculture. PhD Ag. Sc.Univ. of Western Australia (ADELAIDE).

Hassen, H. and Seklani, H. (1992). Observation sur la pollinisation de la luzerne porte graines par l'abeille domestique (Apis mellifica. L ). Ann. INRAT 63 (21).

Hassen, H. (1994). Evaluation agronomique de quelques génotypes de vesce en Tunisie. Revue El AWAMIA, 87: 63-75. 
Jahier, J., Chevre, F., Delourme, R., Eber, F., Tanguy, A. M. et le Groupe de travail INRA (Cytologie et Cytogénétique). (1996). Techniques de cytologie végétale. Ed. Joseph Jahier. Ouv. INRA, 183p.

Mansat, P. Picard, J. (1966). Création de tétraploïdes et sélection préalable au niveau diploïde. Acta. Agric. Scand., 16: 33-37.

Martin, A., Gonzalez, A. (1981). Factors influencing fertility of a tetraploid in Vicia faba:_Physiology and Breeding pp. 329345. Ed. by R. Thompson, Martinus Nijhoff Publishers, The Hague, The Netherlands.

Maxted, N. (1995). An ecogeographical study of Vicia subgenus Vicia. IPGRI: 81-83.

Morthorpe, K. J., Jones, W. A. (1988). Honey bee pollination of pasture legume seed crops in Australia. Proceedings of Second Australian and International Bee Congress: 144-149.

Msustat. (1986). An intractive statistical analysis package by Richard E. Lund. Vers., 3.20. Serial No., 20075. Montana State University. USA.

Maizonnier, D. Picard, J. (1970). Le manque de fertilité chez le trèfle violet autotétraploïde (Trifolium pratense L.). II. Etude de quelques aspects de l'aneuploïdie. Ann. Amélior. Plantes, 20(4) :407-420.

Povilaitis, B. Boyes, J. W. (1956). A cytological study of autotetraploid red clover. Amer. J. Bot, 43: 169-174.

Raina, S. N., Yamamoto, K., Murakami, M. (1989). Interspecific hybridization and its bearing on chromosome evalution in Vicia narbonensis (Fabaceae). Plant. Syst. Evol., 167: 201-217.

SAS. (1990). SAS user's guide: SAS STAT, SAS BASIC. Version 6. Fourth edition. SAS incl, Box 8000. Cary, NC 27512-8000, Cary, NC: SAS institute INC.

Schulte-Motel, J. (1972). Die archäologischen Reste der Ackerbohne, Vicia faba L. und die Genese der Art. Kulturpflanze 19: 321-358.

Zohary, D. Hope, M. (1988). Domestication of plants in the Old World. Clarendon, Oxford.

Table 1. Analysis of variance for fertility traits in diploid and tetraploid plants under selfing and cross-pollination regime

\begin{tabular}{llllll}
\hline & Means & & PLD & RM & Interactions \\
& & & & & \\
\hline SP & 374.1 & 46.5 & 0.0001 & 0.2861 & 0.9780 \\
P/F & 0.9 & 0.7 & 0.0001 & 0.0001 & 0.0001 \\
S/P & 3.5 & 1.4 & 0.0001 & 0.0045 & 0.5489 \\
S/F & 3.1 & 0.5 & 0.0001 & 0.0116 & 0.3629 \\
PEP & 6.7 & 64.0 & 0.0001 & 0.0011 & 0.0021 \\
W10 & 3.1 & 4.2 & 0.0001 & 0.8167 & 0.5690 \\
PL & 4.8 & 5.7 & 0.0001 & 0.0648 & 0.4988 \\
& & & & & \\
\hline
\end{tabular}

PLD : ploidy level ; RM : reproduction mode; S/P : number of seeds/plant ; P/F : number of flowers giving pods ; $\mathrm{S} / \mathrm{P}$ : seeds per pod ; S/F : seeds/flower ; PEP : percentage of empty pods ; W10= weight of 10 seeds (g); PL: pod length $(\mathrm{cm})$. 
Table 2. Effect of the reproductive system on the variation of some fertility parameters in diploid and tetraploid plants

\begin{tabular}{lllllll}
\hline \multicolumn{3}{c}{ Diploids } & \multicolumn{5}{l}{ Tetraploids } \\
\hline & SEL & FP & S & SEL & FP & S \\
\hline SN & 388.6 & 359.7 & NS & 61.7 & 31.2 & HS \\
P/F & 0.93 & 0.94 & NS & 0.94 & 0.73 & HS \\
S/P & 3.66 & 3.42 & NS & 1.45 & 1.30 & HS \\
S/F & 3.20 & 3.02 & NS & 0.63 & 0.28 & HS \\
PEP & 6.40 & 7.00 & NS & 54.90 & 73.10 & HS \\
& & & & & &
\end{tabular}

$\overline{\mathrm{SN}}=$ seed number per plant; Pods/Flower; S/P: seeds/pod; Seeds/Flower; $\%$ of empty pods; SEL: selfing; FP: free pollination

Table 3. Average number of ova per gyneaceum and seed per pod in diploids and tetraploids

\begin{tabular}{lll}
\hline & Diploïdes & Tétraploïdes \\
\hline Ova per gyneaceum & 5.83 & 5.62 \\
Prob(t)>t.obs & 0.2391 & 0.2391 \\
Signification & NS & NS \\
Seeds per pod & 3.54 & 1.37 \\
Prob(t)>t.obs & 0.0045 & 0.0045 \\
Signification & HS & HS \\
\hline
\end{tabular}

HS : highli significant $(\operatorname{Pr}<0.001)$; NS : not significant $(\mathrm{P}>0.05)$.

Table 4. Pollen germination rate in diploid and tetraploid plants

\begin{tabular}{lllll}
\hline & PGR & Amplitude & F. observed & Prob $>$ F \\
\hline DIP & $68.6 \%$ & $40.0-95.6$ & 116.1 & 0.0001 \\
TET & 32.9 & $21.8-48.5$ & & \\
\hline
\end{tabular}

Table 5. Analysis of variance of the different meiotic configurations frequencies observed in tetraploid plants

\begin{tabular}{lllll}
\hline $\begin{array}{l}\text { Chromosomical } \\
\text { associations }\end{array}$ & mean/Cell & $\mathrm{F}$ & Prob $>\mathrm{F}$ & $\mathrm{S}$ \\
\hline Univalents & 0.69 & 1.280 & 0.1942 & $\mathrm{NS}$ \\
Bivalents & 8.10 & 4.96 & 0.0001 & $\mathrm{HS}$ \\
Trivalents & 0.32 & 1.46 & 0.0962 & $\mathrm{NS}$ \\
Quadrivalents & 2.55 & 3.86 & 0.0001 & $\mathrm{HS}$ \\
\hline
\end{tabular}

$\mathrm{F}=\mathrm{F}$ observed; $\mathrm{S}=$ signification; HS: highly significant $(\operatorname{Pr}<0.001)$; NS: not significant at $\operatorname{Pr}>0.05$ 


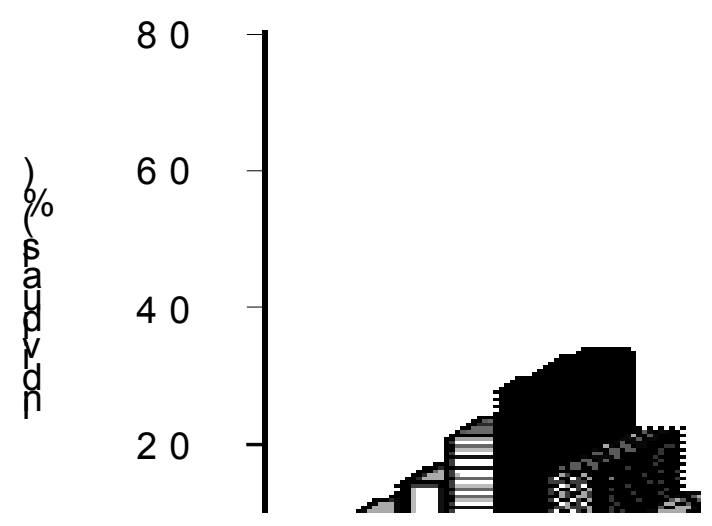

Figure 1. Classification of pods according to the number of seeds in Vicia narbonensis diploid (DIP) and tetraploid (TET)

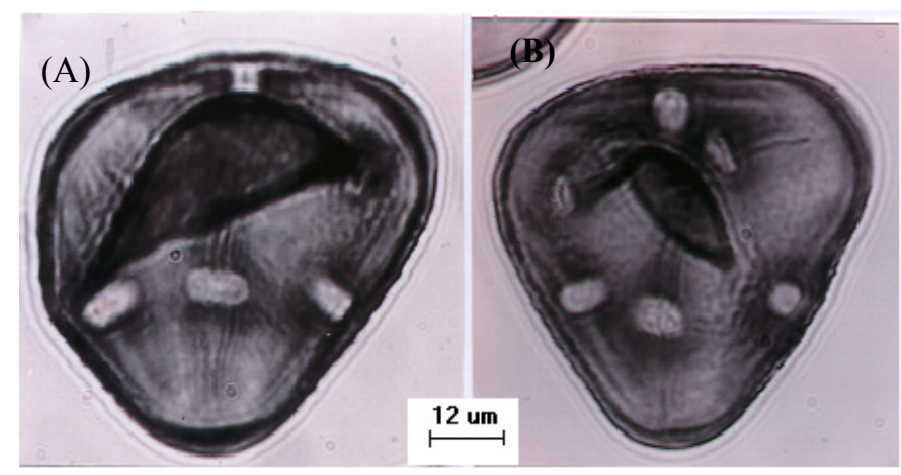

Figure 2. Pollen grains with symmetry equal to 4 (A) and 6 (B) in Vicia narbonensis autotetraploid
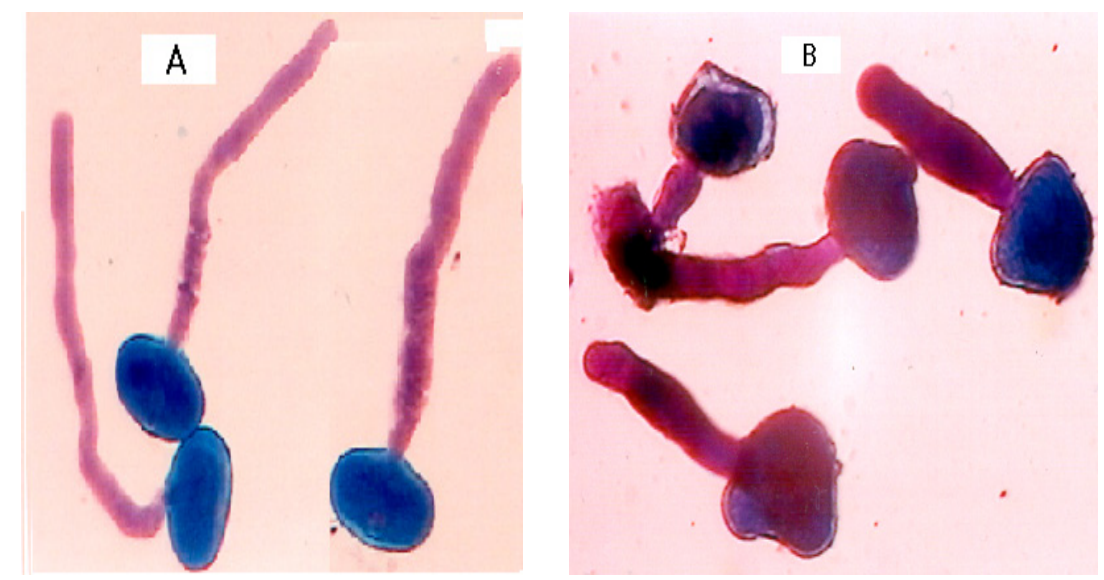

Figure 3. Germinated pollen of Vicia narbonensis L. diploid (A) and tetraploid (B) 


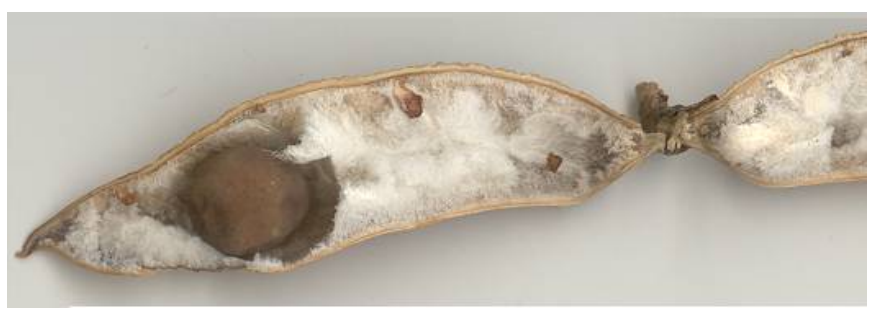

Figure 4. Ripe pod of tetraploid Vicia narbonensis showing the first two aborted seeds
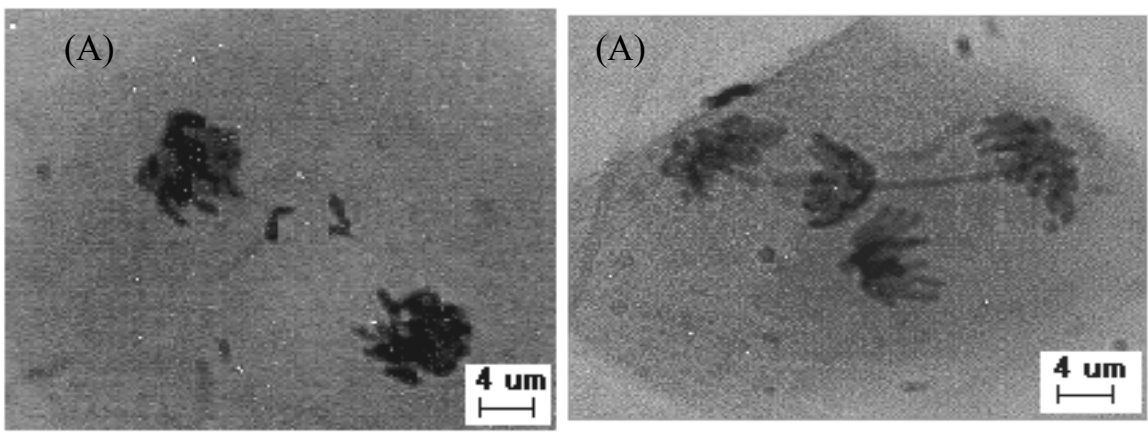

Figure 5. Abnormalities of anaphase; A: straggler chromosome (anaphase I); B: chromatidic bridge (anaphase II) 